\title{
The Self-Serving Bias and Beliefs about Rationality
}

\author{
Todd R. Kaplan* \\ Department of Economics \\ University of Exeter \\ Exeter, UK
}

\author{
Bradley J. Ruffle \\ Department of Economics \\ Ben-Gurion University \\ Beer Sheva, Israel
}

December 2002

\begin{abstract}
Most previous experiments attempting to establish the existence of the selfserving bias have confounded it with strategic behavior. We design an experiment that controls for strategic behavior (Haman effects), and isolates the bias itself. The self-serving bias that we measure concerns beliefs about the rationality of others. We find very limited support for the existence of the bias. To help understand why the bias seems to hold in some settings but not in others, we discuss a distinction between biases that are self-serving and those that are actually self-defeating.
\end{abstract}

Keywords: self-serving bias, beliefs about rationality, Haman effects, p-beauty contest game, gender effects, field of study effects, self-defeating.

Journal of Economic Literature classification number: C92.

\footnotetext{
*We thank Yakov Gilboa for dedicated research assistance, as well as Linda Babcock, Colin Camerer, Robert Kurzban, Orit Tykocinski, seminar participants at the ESA Annual Meetings in Lake Tahoe and the Russell Sage's behavioral economics reunion and especially an anonymous referee of this journal for valuable comments. Financial support was provided by the Department of Economics at Ben-Gurion University.

${ }^{\dagger}$ Correspondence to: Bradley Ruffle, Department of Economics, Ben-Gurion University, P.O.B. 653, Beer Sheva, 84105, Israel, fax: 972-8-6472941, e-mail: bradley@bgumail.bgu.ac.il, websites: http://econ.bgu.ac.il/facultym/bradley and http://www.toddkaplan.com
} 


\section{Introduction}

Now Haman had just entered the outer court of the king's palace to speak to the king about having Mordecai hanged on the gallows that he had prepared for him. So the king's servants told him, "Haman is there, standing in the court." And the king said, "Let him come in." So Haman came in, and the king said to him, "What shall be done to the man whom the king delights to honor?" And Haman said to himself, "Whom would the king delight to honor more than me?" and Haman said to the king, "For the man whom the king delights to honor, let royal robes be brought which the king has worn, and the horse which the king has ridden, and on whose head a royal crown is set; and let the robes and the horse be handed over to one of the king's most noble princes; let him array the man whom the king delights to honor, and let him conduct the man on horseback through the open square of the city, proclaiming before him: 'Thus shall it be done to the man whom the king delights to honor." Then the king said to Haman, "Make haste, take the robes and the horse, as you have said, and do so to Mordecai the Jew who sits at the king's gate. Leave out nothing that you have mentioned." The Old Testament, Ester $6: 4-10$.

On the Jewish holiday of Purim, the book of Ester is read to celebrate the foiling of Haman's plans to destroy the Jewish people. In the passage above, the king attempts to elicit Haman's objective beliefs or assessment about what should be done for the person the king wishes to honor. Believing that he is that person, Haman responds to the king's question not with his true beliefs about the reward such a person deserves, but with a strategically manipulated answer. The passage illustrates the difficulty in eliciting a person's true beliefs: the person may be responding in his own strategic self-interest.

We define a Haman effect as an outcome in which an individual responds strategically to an attempt to elicit his true beliefs. The individual responds strategically because he (correctly or incorrectly) perceives that his response will affect his payoff. Thus, the inquirer obtains strategically manipulated beliefs, rather than the true ones. In the case of Haman, hindsight reveals that he incorrectly perceived that his response to the king's question was relevant to his own payoff: all along the king intended to reward not him but Mordecai. 
Experiments in economics and psychology designed to elicit participants' true beliefs or true preference for fairness are confronted with the challenge of controlling for Haman effects. The use of sequential and interdependent decisions, repeated games, or contextually rich settings in which context has not been introduced one variable at a time are all sources of the Haman effect and pose difficulty in the interpretation of observed behavior. More generally, the inability to control completely for strategic considerations often opens up the data to alternative hypotheses unintended by the researchers.

In the economics literature, self-serving biases are used to explain unusually high rejection rates in two-player and three-player ultimatum games with differential outside options (Knez and Camerer, 1995), the high disagreement rates in bargaining games (Babcock and Loewenstein, 1997), the discrepancy between plaintiffs' and defendants' assessments of fair settlements in tort cases (Babcock et al., 1995) and the frequency of strikes among public school teachers (Babcock et al., 1996).

The main difficulty with these studies is their inability to separate out the unintentional or subconscious alteration of beliefs from the intentional or conscious calculation for gain. We suggest that the former constitutes the self-serving bias while the latter is a form of Haman effect not to be included as part of the bias. ${ }^{1}$

Moreover, all of the above-cited examples concern individuals' differing perceptions about what constitutes a fair outcome in settings where multiple focal points exist. In fact, Babcock and Loewenstein (1997, p. 110) refer to the self-serving bias as a tendency "to conflate what is fair with what benefits oneself." We suggest that this definition is too restrictive, that the self-serving bias need not be related to fairness. ${ }^{2}$ We offer the

\footnotetext{
${ }^{1}$ Elsewhere (Kaplan and Ruffle, 1998) we have expressed our reservations about the interpretation of the results of some of these experimental studies that claim to have found support for the self-serving bias. There, we offer alternative explanations that cannot be ruled out and may explain the data in the twoplayer and three-player ultimatum games reported by Knez and Camerer (1995), and the bargaining game results of Roth and Murnighan (1982) interpreted as evidence of the bias by Babcock and Loewenstein (1997). To avoid repetition and to save space, we refer the interested reader to this reference (or to a more detailed exposition available for download at http://econ.bgu.ac.il/facultym/bradley/ssb.pdf).

${ }^{2}$ Babcock and Loewenstein (1998) recognize explicitly that the self-serving bias "extends beyond biased considerations of fairness" (p. 244) and implicitly through the numerous examples of the bias they cite from the psychology literature (Babcock and Loewenstein, 1997).
} 
following more general definition of the self-serving bias, which captures the numerous examples of the bias in the social psychology and economics literatures as well as the setting examined in this paper.

Definition A self-serving bias exists where an individual's preferences affect his beliefs in an optimistic way, a way that makes things appear better than they are from the individual's point of view.

Beliefs may be about one's own ability, the environment, another player's type, or about what constitutes a fair outcome. The appearance that things are better can be understood as meaning that the individual's expected utility is higher with self-serving beliefs than without them for a given set of strategies; namely, $E\left[U\left(s_{i}, s_{-i}\right)\right.$ |biased beliefs $]$ $>E\left[U\left(s_{i}, s_{-i}\right) \mid\right.$ unbiased beliefs $]$. However, it is often the case that self-serving beliefs lead the individual or others interacting with the individual to change their strategies. The change in strategies may increase or decrease the individual's actual expected utility in comparison to the person who possesses unbiased beliefs from the outset. In section 4 we provide examples of both possibilities.

Wishful thinking is a specific type of self-serving bias. It occurs when an individual overweights the likelihood of a favorable event or underweights the likelihood of an unfavorable one. Extending the domain of wishful thinking beyond favorable events to include beliefs about ability, player type or a fair outcome would equate wishful thinking with the self-serving bias. Forsythe, Rietz, and Ross (1999) find evidence of wishful thinking in a market in which traders increase the prices of state-contingent claims associated with their preferred outcomes. Bar-Hillel and Budescu (1995), by contrast, conduct a battery of experiments in contextually rich and contextually sterile environments and find little to no evidence of wishful thinking in any of their experiments. In one of their experiments (Study 4), subjects were asked each week over a four-week period to estimate the probability that the Dow Jones Industrial Average (DJIA) would change by more than 20 
points in a week. Half of the subjects were eligible for a cash prize if the DJIA changed by more than 20 points, while the other half were eligible if it changed by less than 20 points. Bar-Hillel and Budescu found no significant differences in the probability judgements of these two groups in any of the four weeks of their study.

The objective of this paper is to design a simple experimental test of the self-serving bias that controls for Haman effects. We achieve this control through a number of means. First, our game is one shot. Second, in order to elicit an individual's true beliefs, we design a game in which each individual has an incentive to reveal his true beliefs in order to win a prize, while at the same time the payoff that each individual receives is unrelated to his response in the game. We choose a sterile environment to minimize the chance that individuals might even mistakenly believe that their individual payoffs are somehow related to their responses in the game. Our test of the bias is unrelated to fairness perceptions. Instead, our experimental design, a modified one-shot version of the p-beauty contest game, tests whether individuals hold self-serving beliefs about the rationality of others.

In the next section, we describe the experiments we conduct and the experimental hypotheses. We present our results in section 3 followed by a discussion in section 4 . Section 5 concludes.

\section{Experimental Design, Procedure and Hypotheses}

\subsection{Experimental Design}

In the guessing game (Moulin, 1986), or p-beauty contest game as it is more frequently called, players simultaneously choose a number in the closed interval $[0,100]$. The player whose number is closest to $p$ times the mean of all numbers chosen (where $p$ is a parameter that is common knowledge to all players) wins a predetermined cash prize. All other 
players earn zero. The unique Nash equilibrium of this game, for $p \in[0,1)$, is for all players to choose zero. Nagel (1995) first tested this game experimentally to investigate players' depth of reasoning. A player will choose a number greater than zero if he is irrational (zero-order beliefs), if he is rational but believes others are irrational (firstorder beliefs), or, more generally, if at some level in his infinite hierarchy of beliefs, he specifies some irrationality.

We modify the guessing game in a way that allows us to test for biased beliefs about the rationality of others. ${ }^{3}$ In addition to paying a fixed prize of 400 new Israeli shekels (NIS) (approximately $\$ 100 \mathrm{US})^{4}$ to the subject whose guess is closest to $2 / 3$ times the average of all guesses, our design pays a variable payoff to each subject. There are 30 subjects in each session, each subject with an identity number from 1 to 30. Those subjects with an odd identity number (hereafter to be frequently referred to as odd subjects, for brevity) receive as a variable payoff the mean guess of all 29 other chosen numbers divided by four. All even-numbered subjects (henceforth even subjects) receive 100 minus the mean guess of all 29 other subjects, this number divided by four. ${ }^{5}$ Dividing by four renders our subject payments affordable while at the same time worthwhile for the student subjects. The payoff structure implies an average variable payoff of 12.5 shekels. Our intention was to set the expected variable payoff of the same order of magnitude as the expected fixed payoff. This balance was struck in order that subjects' elicited preferences as a function of their identity numbers are over non-trivial amounts of money and so that the incentive to win the fixed prize is meaningful.

By excluding a subject's guess from his variable payoff, we control for strategically manipulated guesses. Furthermore, by playing the game only once, there is no room to

\footnotetext{
${ }^{3}$ With the intent of studying learning behavior, Nagel and Duffy (1997) have tested experimentally variations of the p-beauty game in which the winner is the person who chooses the number closest to $1 / 2$ the median, mean or maximum of all numbers chosen.

${ }^{4}$ At the time the experiments were conducted the exchange rate ranged from $\$ 1$ US $=3.5$ NIS to $\$ 1$ $\mathrm{US}=4.09$ NIS.

${ }^{5}$ Appendix A contains the instructions. The actual instructions used were translated to Hebrew and are available upon request from the authors.
} 
manipulate one's guess in order to influence guesses in the subsequent period. Instead, a subject's guess summarizes his beliefs about everyone else's guesses.

Let us examine now how the self-serving bias comes into play. Recall that the definition of the bias says that preferences influence beliefs in a way that favors one's own payoff. Odd subjects have a preference for a high average to obtain a high variable payoff. Therefore, according to the bias, they should believe that others will choose high numbers (i.e. exhibit a relatively low level of rationality). Thus, an odd subject should guess high in order to maximize his chance of winning the fixed prize. Conversely, the lower the average, the higher the payoffs to the even subjects. Thus, an even subject who makes a self-serving guess should assume a higher level of rationality and guess low. Therefore, the self-serving bias predicts that the guesses of the subjects with odd identity numbers will be greater than those with even identity numbers.

It is important to emphasize the nature of the psychological mechanism that underlies the self-serving bias in this design. Previous experiments have confounded the conscious calculation for gain with the subconscious alteration of beliefs. The former we do not consider to be a part of a cognitive self-serving bias, but rather a form of (self-)strategy, as exemplified by Haman in the book of Ester. By excluding a subject's own guess from his variable payoff and by conducting this game one shot, we have controlled for such Haman effects. We also test for subjects' understanding of the game to identify those who may incorrectly perceive that their guess affects their variable payoff. Thus, the bias in our design operates through the subconscious alteration of beliefs.

\subsection{Experimental Procedures}

We conducted seven sessions, each with 30 subjects. Three sessions consisted of economics students and four sessions consisted of psychology students. All subjects were recruited during various undergraduate classes in economics and psychology. The exper- 
iment required about 25 minutes with an additional 15 minutes to calculate and count out subjects' payments. In each session, one subject earned 400 shekels plus his variable payoff. The remaining 29 subjects earned their variable payoff only. Variable payoffs ranged from 7 shekels to 19 shekels. ${ }^{6}$

We took a few measures to clarify the workings of the experiment to subjects. First, after reading the instructions, but before making their choice of number, subjects were presented two examples based on randomly chosen numbers. In both examples, a number from 0 to 100 was drawn from a plastic bag for each of four imaginary subjects (two odd subjects and two even subjects). The first example was solved explicitly on the board so that all subjects could observe how subjects' variable and fixed payoffs are calculated. ${ }^{7}$ Clarifying questions were permitted before proceeding to the second example. For the second example, we again drew four numbers randomly, but now asked the subjects to solve for the payoffs to the four imaginary subjects. This required subjects to think through the design and allowed us to test for their understanding by the correctness of their answers. We provided subjects with calculators to minimize the chance of arithmetic errors and motivated them by using the most number of correctly answered questions (payoffs) as a tie-breaker in case two or more subjects in the experiment chose numbers equidistant from $2 / 3$ of the average.

After writing the four numbers from the second example on the board, subjects calculated the imaginary subjects' variable and fixed payoffs. Questions were answered and subjects were given ample time to choose a number. Upon completion the instruction sheets with the subjects' choice of number (and their answers to the payments to the four imaginary subjects) were collected. While waiting for their payments to be computed, each subject explained on a cue card why he chose the number he did. Subjects were

\footnotetext{
${ }^{6}$ Note that the minimum wage in Israel at the time - the wage earned by most students who work part-time - was 13 shekels an hour.

7 Only multiples of 10 from 0 to 100 were in the plastic bag. The subjects were told that this was to simplify the payment calculations and that they were free to choose any real number from 0 to 100 inclusive.
} 
subsequently called one at a time to collect their payments and submit their cue cards.

From examining subjects' calculations of the four imaginary subjects' payoffs, at least $58 \%$ of the 210 student subjects demonstrated a full comprehension of the design by writing down the correct payoffs for all four. Among those subjects who did not write down the correct payoffs for all four subjects, the most benign error was not dividing the winner's payoff by 4 (2.8\% of the subjects); $2.4 \%$ forgot to include the winner's variable payoff; $17.6 \%$ did not indicate a winner at all; $10 \%$ of the subjects wrote down the right formulae for the odd and even variable payoffs but made a single arithmetic error; two $(0.95 \%)$ subjects simply did not fill in the payoffs to the imaginary subjects. The remaining $9.5 \%$ of the subjects made a systematic error in calculating the variable payoffs of either the two odd or the two even imaginary subjects. ${ }^{8}$ These latter subjects $(9.5 \%)$ provide a lower bound on the percentage of total subjects whose lack of understanding of the payoff structure may inhibit them from making a well-informed guess.

\subsection{Controlling for Alternative Hypotheses}

We settled on this design and the particular variable payoff structure both for the relative simplicity of the variable payoff structure and its ability to control for alternative hypotheses. By conducting only one round of this game and by not including one's own guess in the calculation of a subject's variable payoff, strategic play and Haman effects are eliminated. Additional hypotheses of concern to us were altruism and beliefs about altruism. Overall altruism is nullified in this design: increasing one's guess improves the variable payoff of the odd subjects by the same measure that it reduces that of the evens. Furthermore, beliefs that others are altruistic should not cause a subject to alter his guess since, as shown above, the altruistic motive does not affect others' guesses and therefore need not affect one's own. On the other hand, group altruism may cause odd subjects to

\footnotetext{
8 Three subjects in this group made an additional error associated with the winner, thereby explaining the fact that the percentages above sum to 101.25.
} 


\begin{tabular}{|c|c|c|c|c|c|c|c|}
\hline \multirow{2}{*}{$\begin{array}{c}\text { Identity } \\
\text { Number }\end{array}$} & \multicolumn{7}{|c|}{ Hypothesis } \\
\cline { 2 - 8 } & belf-serving & beliefs about & overall & beliefs about & group & beliefs about & insurance \\
odd & $\uparrow$ & ssb & altruism & $\begin{array}{c}\text { overall altr. } \\
\text { altruism }\end{array}$ & group altr. & \\
\hline even & $\downarrow$ & - & - & - & $\uparrow$ & - & $\downarrow$ \\
& - & - & - & $\downarrow$ & - & $\uparrow$ \\
\hline
\end{tabular}

Table 1: The table lists the possible experimental hypotheses and their theoretical effects on the direction of subjects' guesses with odd and even identity numbers. The possible

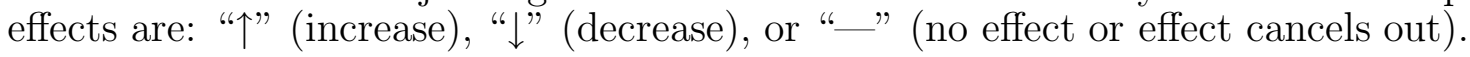

guess high and even subjects to guess low to increase the variable payoffs to those sub-

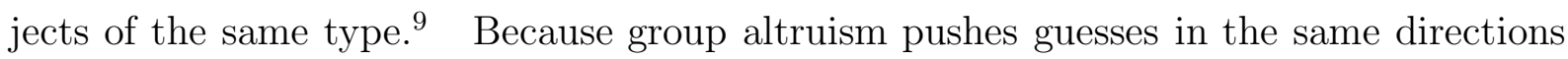
as the self-serving bias, we take several measures to minimize its likelihood and effect. In this way, in the event that odd guesses are greater than even guesses, the confounding is minimal. First, we chose a relatively large group size of 30 subjects, in part, so that the impact of an individual subject's guess on group averages is diffuse. Second, by seating subjects well apart from one another, subject anonymity was maintained. Third, we feel that randomly assigning subjects an odd or even identity number is quite hollow as a symbol of group identity. Finally, explicit calculation of payoffs on the blackboard for the first example presents a sterile, calculating environment for the arousal of any such in-group sentiments.

Even if a subject does not exhibit group altruism, he may believe others do. Yet beliefs about group altruism leave one's own guess unaffected, assuming one believes the odds are equally as likely to exhibit group altruism as the evens. Similar reasoning holds for beliefs about the self-serving bias: if you believe others may be biased in their beliefs about the rationality of others in a way that is self-serving, then you believe the odd subjects will guess high and the evens low. Assuming you believe the self-serving bias

\footnotetext{
${ }^{9}$ The minimalist conditions under which subjects form in-group, out-group distinctions are well documented in the cognitive psychology literature. Consult Tajfel et al. (1971) for the classic reference.
} 
to be equally likely among the odds and the evens (and there is no apparent reason why you should believe one group more susceptible to the bias than the other), then your own guess should remain unchanged.

The only remaining hypothesis is the insurance motive. The insurance motive works in the opposite direction as the bias. If an odd subject fears his variable payoff will be low (a low average of numbers), he will guess low to try to win the fixed prize and if an even subject fears a low variable payoff due to a high average, he will guess high. Table 1 summarizes the various possible motives and their directions.

\section{Results}

\subsection{Data Analysis}

Table 2 presents summary statistics of the guesses of even and odd subjects according to sample population. A visual representation of the data can be found in Appendix B, Figures 1 and 2. We choose to display our data in circle plots. The location of a circle indicates the value of the sample observation. The size of each circle indicates the number of observations at that value. The diagrams are a compact way of accurately representing a sample. For our purposes, they provide a quick and accurate impression of the data and enable us to display many more sample distributions on a single page than is possible with more standard histograms. The triplet to the right of each circle plot in Figure 2 indicates the (mean, median, sample size) for that sample. In Figure 1, the sample size is omitted since there are 15 observations of odd and even guesses in each session. The paper's first main result follows from a comparison of the last two circle plots in Figure 1 as well row 1 of Table 2 .

Observation 1 Subjects with odd identity numbers did not guess significantly higher than those with even identity numbers. That is, the aggregate data does not support the 


\begin{tabular}{|c|c|c|c|c|}
\hline Population & $\begin{array}{c}\text { odd } \\
\text { mean, median }\end{array}$ & $\begin{array}{c}\text { even } \\
\text { mean, median }\end{array}$ & $\begin{array}{c}\text { Mann-Whitney } \\
\text { test results }\end{array}$ & Obs. \\
\hline Overall & $\begin{array}{l}33.3,33.0 \\
(\sigma=1.54)\end{array}$ & $\begin{array}{c}32.7,27 \\
(\sigma=2.15)\end{array}$ & $\begin{array}{c}\mathrm{Z}=-1.247 \\
(\mathrm{p}=.213)\end{array}$ & 210 \\
\hline $\begin{array}{c}\text { Female } \\
\text { Psychologists }\end{array}$ & $\begin{array}{c}37.7,34.0 \\
(2.02)\end{array}$ & $\begin{array}{c}33.9,28.0 \\
(3.71)\end{array}$ & $\begin{array}{c}\mathrm{Z}=-2.238 \\
(.025)\end{array}$ & 84 \\
\hline $\begin{array}{c}\text { Female } \\
\text { Economists }\end{array}$ & $\begin{array}{c}30.3,33.0 \\
(2.28)\end{array}$ & $\begin{array}{c}33.5,27.0 \\
(3.88)\end{array}$ & $\begin{array}{c}\mathrm{Z}=-.011 \\
(.991)\end{array}$ & 47 \\
\hline $\begin{array}{c}\text { Male } \\
\text { Psychologists }\end{array}$ & $\begin{array}{c}31.1,22.0 \\
(5.12)\end{array}$ & $\begin{array}{c}27.5,27.0 \\
(5.08)\end{array}$ & $\begin{array}{c}\mathrm{Z}=-.283 \\
(.777)\end{array}$ & 32 \\
\hline $\begin{array}{c}\text { Male } \\
\text { Economists }\end{array}$ & $\begin{array}{c}27.0,25.5 \\
(3.72)\end{array}$ & $\begin{array}{c}30.1,26.0 \\
(4.23)\end{array}$ & $\begin{array}{c}\mathrm{Z}=-.496 \\
(.620)\end{array}$ & 41 \\
\hline
\end{tabular}

Table 2: Summary statistics for the guesses of the even and odd subjects in the overall population (row 1) as well as each of the subpopulations (rows 2-5). In each cell the group's mean guess appears to the left of the median guess with the standard error in parentheses below. The second-to-last column displays the results from two-tailed, Mann-Whitney tests ( $\mathrm{p}$-values in parentheses). The last column indicates the number of observations in the sample population. 
existence of the self-serving bias.

The mean (median) guess of the odd subjects is $33.3(33.0)(\mathrm{N}=105)$ compared to $32.7(27.0)(\mathrm{N}=105)$ for the even subjects. We cannot reject the null hypothesis that the sample distributions are the same (p-value from Mann-Whitney test=.213). ${ }^{10,11,12}$

With three sessions involving economics students and four made up of psychology students, we examined the data on a finer level. It may be the case that the subjects from one field of study significantly display the bias while the students from the other field display no bias at all or even a reverse bias, thereby dampening the bias in the aggregate data. Field of study has been shown to matter in a variety of other contexts. ${ }^{13}$ We believe it may matter here as well. For instance, economists may have an easier time ignoring the variable payoff over which they have no control. The other observable variable that may be a determinant of the existence of the bias is the subject's gender. Elsewhere gender often plays a role in risk-taking behavior, altruism, fairness and trust. ${ }^{14}$

\footnotetext{
10 All p-values reported in parentheses in this section are results from two-tailed, Mann-Whitney nonparametric tests and refer to 1 - probability that we can reject the null hypothesis that the two (odd and even) sample distributions are drawn from the same underlying population distribution.

${ }^{11}$ Focusing on those subjects who correctly answered the hypothetical, pre-experiment questions does not help the bias: we found absolutely no relation between subjects' ability to answer these questions and the self-serving bias or their guesses. For instance, the average guess among the $58 \%$ of the subjects who answered all questions correctly was 33.4 compared to 32.5 for those who didn't.

12 The difference between the mean and median guesses of the even subjects suggests the possible presence of outliers. If we exclude all guesses above 66.66 on the basis that they are irrational or weakly dominated by guessing exactly 66.66 , then the self-serving bias turns up significant $(\mathrm{p}=.039)$. This holds because $9 / 13$ guesses above 66.66 were made by even subjects. Furthermore, the seven highest guesses (above 80) were all made by even subjects. (See Figure 1.) One explanation for these findings is that the number "100" that appears in the calculation of the even subjects' variable payoff of "100 minus the average" provides an anchor upon which some evens based their guesses. The processing of the number "100" subconsciously pushes upward some even subjects' guesses, in the opposite direction of the bias.

13 Frank, Gilovich and Regan (1993) survey the evidence from public goods experiments, ultimatum games and prisoner's dilemma experiments in support of the view that economics students act in a more self-interested and less cooperative way than non-economics students. Yezer et al. (1996) show that economics students are more honest than non-economists in a lost-letter experiment. Ruffle and Tykocinski (2000) find that psychologists estimate more accurately than economists the costs of identical gift items.

${ }^{14}$ Eckel and Grossman (2001) survey the experimental results that test for a gender effect in public goods games, ultimatum games and dictator games. In trust games, both Croson and Buchan (1999) and Chaudhuri and Gangadharan (2001) find that women responders return significantly higher amounts of money to the proposers than men do. Chaudhuri and Gangadharan's results show that men are more trusting than women, while Croson and Buchan find no difference between men and women proposers.
} 
Observation 2 Among the four subgroups (female economists, male economists, female psychologists, male psychologists), only female psychologists exhibit the bias.

As Table 2 shows, the guesses of odd female psychologists are significantly higher than those of their even counterparts. This finding is all the more striking when contrasted with the female economists who show no sign of a bias whatsoever $(\mathrm{p}=.991)$. Male psychologists similarly show little sign of the bias, while the guesses of odd male economists are actually slightly lower than those of even male economists $(p=.620) .{ }^{15}$

\section{Thoughts on the Relevance of the Self-Serving Bias}

We designed an experimental test for the self-serving bias in which the subject's strategy space is very simple, namely, choose, one time, a single number between 0 and 100 inclusive. The context we selected is a sterile one. Even in contextually rich environments, widespread pervasiveness of the bias remains to be shown. Aside from difficulties in ruling out alternative hypotheses when context is not introduced into the experimental design one variable at a time, other research in contextually rich settings does not find broad support for the bias. Dahl and Ransom (1999) find very limited evidence of a financially motivated self-serving bias among Mormons in their own determination of what constitutes income for the purpose of tithing. Bar-Hillel and Budescu (1995) find little to no evidence of the bias in their series of contextually rich and contextually sterile experiments. Besides the Haman effect, what other reasons might explain why the self-serving

\footnotetext{
${ }^{15}$ To show that the significant bias found among female psychologists, but not among female economists is not simply the result of the female psychologists' larger sample size (i.e., greater statistical power), we randomly sampled 24 (23) female psychologists with odd (even) identity numbers to match the corresponding sample sizes of the female economists. We then performed the Mann-Whitney test on this random sample. We repeated this exercise 10,000 times and found that the p-value of the female psychologists was smaller than that of the female economists 9,989/10,000 times and was significant at the $5 \%$ level or less 5,028 times (one-tailed test). We repeated this exercise to match the sample sizes of the male psychologists (i.e., 15 odd and 17 even) and again found the p-value of the female psychologists to be smaller than that of the male psychologists $9,369 / 10,000$ times and significant at the $5 \%$ level or less 3,433 times (one-tailed test).
} 
bias appears to obtain in some settings while not in others?

One clue may be the functionality of the bias. In many contexts the self-serving bias might be better termed "self-defeating", since individuals who display the bias do so at a cost to their own monetary payoff. A historical perspective suggests that evolutionary forces may drive out self-serving biases that are costly. Examples of maladaptive biases are ones that lead to complacency, laziness or the unwillingness to take necessary precautions or to develop oneself further. Legends are all that remain to record the stories of the countless tribes and individuals who viewed their strength as superior, their foodsources as assured, or their inventions as invincible. Along these lines, several of the self-serving bias studies test for a bias that is in actual fact self-defeating. Our p-beauty contest game scenario and the stock market prediction scenario studied by Bar-Hillel and Budescu are two such examples. Another example is the high school kid whose self-serving beliefs motivate him to devote all of his time to playing basketball, rather than studying, despite having no chance at making the NBA.

On the other hand, there is considerable evidence that some self-serving biases may well be beneficial. Taylor and Brown (1988) and Taylor (1989) review a large body of research that suggests that self-serving beliefs about one's ability, about the degree of control one possesses over a situation and about one's future "typically lead to higher motivation, greater persistence at tasks, more effective performance, and, ultimately, greater success" (Taylor, p. 64). ${ }^{16}$ In addition, an individual who processes information self-servingly in these areas will be "happier, more caring, and more productive than the individual who perceives this same information accurately" (Taylor and Brown, p. 205).

In negotiations, whether a cognitive bias is self-serving or self-defeating depends on whether one party observes the other's self-serving bias and whether the party is willing to allow his behavior to be influenced by the other's bias. Heifetz and Segev (2001)

\footnotetext{
${ }^{16}$ Ignoring physiological and psychological benefits from maintaining self-serving beliefs, greater success is still self-defeating if the cost of the additional effort exerted exceeds the benefits from the higher probability of success.
} 


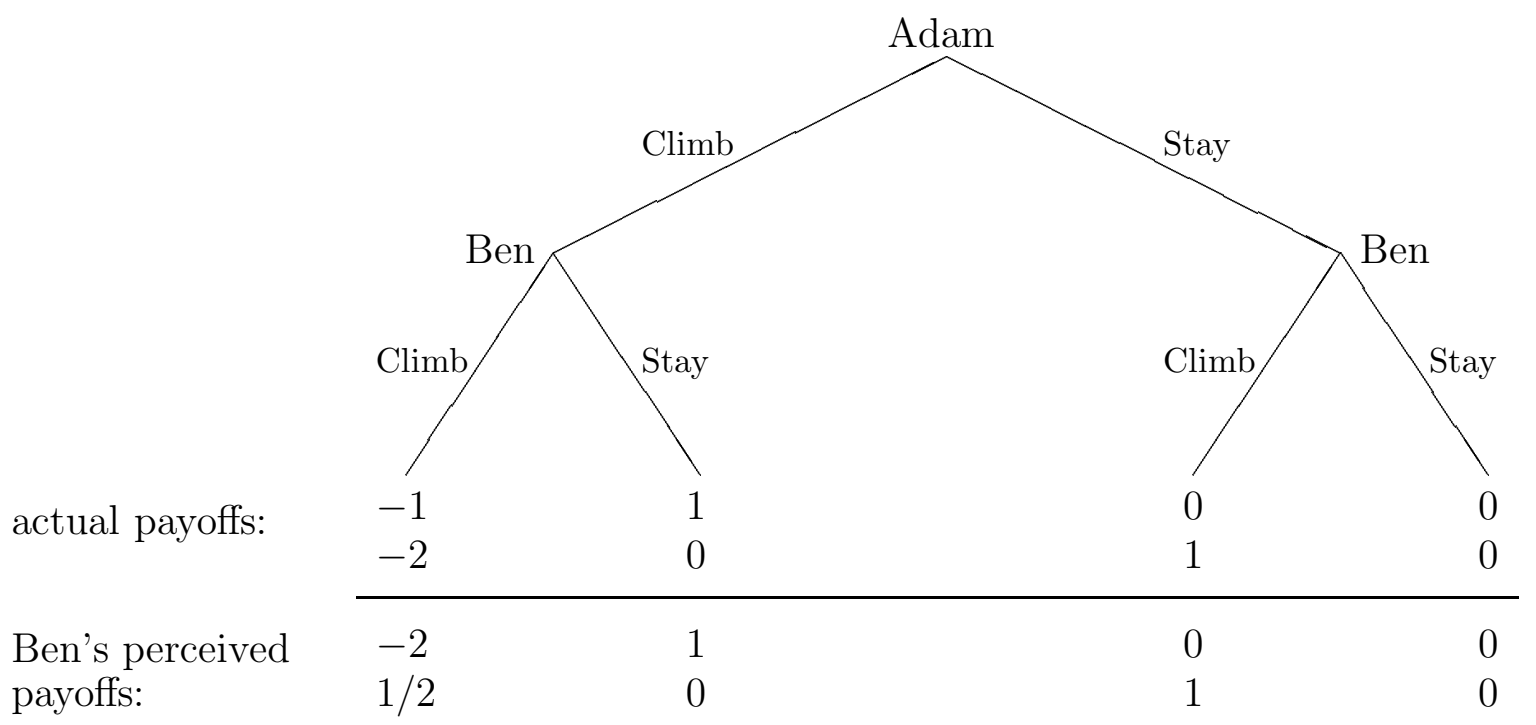

Figure 3: Extensive form of the king of the hill game. The actual payoffs appear above the horizontal line, while Ben's self-serving perception of the payoffs are below the line.

develop an evolutionary model of bargaining in which one negotiator displays a selfserving bias regarding the share of the surplus he deserves. Observing this bias, the opponent adjusts his behavior to accommodate the toughness of the biased negotiator. A one-shot, ultimatum game provides a simple illustration of this logic. Suppose the responder believes that if he rejects the proposer's offer, his outside option is, say, $\$ 3$. Even if the proposer knows this to be false and knows the truth to be that the responder will receive nothing in the case of rejection, he should offer at least $\$ 3$ to avoid rejection, as opposed to offering at least $\$ 0$ in the absence of the bias. Consequently, the responder's self-serving bias functions as a commitment to rejecting low offers.

Another scenario in which the self-serving bias is beneficial is a sequential, two-player game we introduce, which we call the "king of the hill" game. The first player, Adam, decides whether to climb the hill or stay at the bottom. Observing Adam's decision, the second player, Ben, also decides whether to climb the hill or remain at the bottom. There is room for only one person at the top of the hill. Adam is the strong, sensitive type: he is capable of pushing Ben from the hill if they both decide to climb it; however, he incurs significant negative utility from fighting. Although weaker, Ben self-servingly 
believes that he is stronger than Adam. Figure 3 displays the extensive form of the game, including the players' payoffs. In the absence of the bias, the unique subgame-perfect equilibrium prescribes that Adam climb the hill and Ben remain at the bottom. With the bias, Ben's perception of the payoffs in the event of (Climb, Climb) is $(-2,1 / 2)$, when in fact the true payoffs are given by $(-1,-2)$. Thus, if Ben possesses these biased beliefs, he will choose to climb the hill if Adam does. As a result, Adam stays at the bottom and Ben climbs the hill in the unique subgame-perfect equilibrium given the perceived payoffs. Thus, Ben's self-serving beliefs about his strength and Adam's awareness of Ben's beliefs lead to an outcome that benefits Ben.

\section{Conclusion}

We motivated this paper by stating that we wanted to design an experimental test for the self-serving bias that controls for alternative hypotheses. We chose a contextually sterile environment to serve this purpose. Such an environment provides a harsh test for the self-serving bias since it offers little opportunity for subjects to retrieve from memory in subjective ways previous experiences that are relevant to their play of the p-beauty contest game. Indeed we find only very limited support for the bias; only one out of four subgroups exhibited the bias.

The conflicting evidence in the literature concerning the existence of the self-serving bias in decision problems calls for further research to delineate the boundaries of the bias' role in decision making. The distinction between self-serving beliefs that are actually self-defeating and those that are indeed self-serving provides one direction.

\section{References}

[1] Babcock, Linda, Xianhong Wang and George Loewenstein (1996) "Choosing the Wrong Pond: Social Comparisons in Negotiations that Reflect a Self-Serving Bias", Quarterly Journal of Economics, 111:1, 1-19. 
[2] Babcock, Linda and George Loewenstein (1997) "Explaining Bargaining Impasse: The Role of Self-Serving Biases", Journal of Economic Perspectives, 11:1, 109-126.

[3] Babcock, Linda and George Loewenstein (1998) "Response from Linda Babcock and George Loewenstein [letter]", Journal of Economic Perspectives, 12:2, 244-245.

[4] Babcock, Linda, Loewenstein, George, Samuel Issacharoff and Colin Camerer (1995) "Biased Judgements of Fairness in Bargaining", American Economic Review, 85:5, 1337-1343.

[5] Bar-Hillel, Maya and David Budescu (1995) "The Elusive Wishful Thinking Effect", Thinking and Reasoning, 1:1, 71-103.

[6] Chaudhuri, Ananish and Lata Gangadharan (2002) "Gender Differences in Trust and Reciprocity", unpublished manuscript, Wellesley College.

[7] Croson, Rachel and Nancy Buchan (1999) "Gender and Culture: International Experimental Evidence from Trust Games", American Economic Review Papers and Proceedings, $89: 2,386-391$.

[8] Dahl, Gordon B. and Michael R. Ransom (1999) "Does Where You Stand Depend on Where You Sit? Tithing Donations and Self-Serving Beliefs", American Economic Review, 89:4, 703-727.

[9] Eckel, Catherine and Philip Grossman (2001) "Differences in the Economic Decisions of Men and Women: Experimental Evidence", in Handbook of Experimental Results, eds. V. Smith and C. Plott, Elsevier: Amsterdam.

[10] Forsythe, Robert, Thomas Rietz and Thomas Ross (1999) "Wishes, Expectations, and Actions: Price Formation in Election Stock Markets", Journal of Economic Behavior and Organization, 39, 83-110.

[11] Frank, Robert, Thomas Gilovich and Donald Regan (1993) "Does Studying Economics Inhibit Cooperation?", Journal of Economic Perspectives, 7, 159-171.

[12] Heifetz, Aviad and Ella Segev (2001) "The Evolutionary Role of Toughness in Bargaining", unpublished manuscript, Tel-Aviv University.

[13] Kaplan, Todd and Bradley Ruffle (1998) "Self-Serving Bias [letter]", Journal of Economic Perspectives, 12:2, 243-244.

[14] Knez, Marc and Colin Camerer (1995) "Outside Options and Social Comparison in ThreePlayer Ultimatum Game Experiments", Games and Economic Behavior, 10, 65-94.

[15] Moulin, Hervé (1986) Game Theory for the Social Sciences, New York: New York Press.

[16] Nagel, Rosemarie (1995) "Unraveling in Guessing Games: An Experimental Study", American Economic Review, 85:5, 1313-1326.

[17] Nagel, Rosemarie and John Duffy (1997) "On the Robustness of Behaviour in Experimental Beauty Contest Games", Economic Journal, 107, 1684-1700. 
[18] Roth, Alvin and Keith Murnighan (1982) "The Role of Information in Bargaining: An Experimental Study", Econometrica, 50, 1123-1142.

[19] Ruffle, Bradley J. and Orit Tykocinski (2000) "The Deadweight Loss of Christmas: Comment", American Economic Review, 90:1, 319-324.

[20] Tajfel, Henri, Billig, M. G., R. P. Bundy and Claude Flament (1971) "Social Categorization and intergroup behavior", European Journal of Social Psychology, 1:2, 149-178.

[21] Taylor, Shelley E. (1989) Positive Illusions: Creative Self-Deception and the Healthy Mind, New York: Basic Books.

[22] Taylor, Shelley E. and Jonathon D. Brown (1988) "Illusion and Well-Being: A Social Psychological Perspective on Mental Health,” Psychological Bulletin, 103:2, 193-210.

[23] Yezer, Anthony, Robert Goldfarb and Paul Poppen (1996) "Does Studying Economics Discourage Cooperation? Watch What We Do, Not What We Say or How We Play", Journal of Economic Perspectives, 10:1, 177-186.

\section{Appendix A: Instructions for Participants}

There are 30 participants in this experiment. You are to choose a number between 0 and 100 inclusive. The participant whose number is closest to $2 / 3$ the average of all numbers chosen wins 400 shekels. In the case of a tie, the prize is divided equally among the winners who answer correctly the most number of questions from the example explained below.

In addition, each participant has an identity number which is either even or odd. There are an equal number of even and odd numbers. Your identity number is written at the top of this page. Participants with odd numbers receive in shekels the average of all 29 other chosen numbers divided by four. Participants with even numbers receive in shekels 100 minus the average of all 29 other chosen numbers, this amount divided by four.

To help you to understand the experiment, the monitor will begin with two examples each consisting of four numbers drawn randomly from the bin at the front of the room. The payments of the first example will be calculated by the monitor and written on the board to demonstrate how the experiment works. For the second example, the monitor will again draw four numbers randomly from the bin. You are asked to indicate the payments to the four imaginary 
participants at the bottom of this page. This is in order to verify your understanding of the experiment. Also, in the case that two or more participants' numbers are equally close to $2 / 3$ the overall average of the chosen numbers, the prize will be divided equally among the winners with the most number of correctly answered questions in example 2 .

After answering the example, please indicate your own choice of number below. After 10 minutes you will be asked to hand in this form and to return to your seat in order to complete the attached explanation card. When your identity number is called, hand the card to the monitor in order to receive your payment.

If you have any questions, please raise your hand and a monitor will come to assist you.

\section{Please fill in the blank with your choice of number}

From example 2, indicate the payments to participants:

31 , 32 , 33 34 


\section{Appendix B: Circle Plots}

Figure 1: Distribution of Guesses by Session: Each horizontal line displays the distribution of guesses from 0 to 100 . The location of a circle indicates the value of a guess. The circle's size reveals the number of guesses at that value according to the legend at the bottom of the graph. Within each of the three economics sessions (Econ 1, Econ 2, Econ 3) and each of the four psychology sessions (Psych 1, Psych 2, Psych 3, Psych 4), the guesses of the odd-numbered subjects are compared to those of the even-numbered subjects. The pair of numbers to the right of each distribution indicates the mean and median guess, respectively. There are 15 odd-numbered and 15 even-numbered subjects in each session.

Figure 2: Distribution of Guesses by Gender and Field of Study: The distribution of guesses of the odd-numbered and even-numbered subjects are displayed according to the four subpopulations, female psychologists, male psychologists, female economists, and male economists. The triplet to the right of each distribution reveals the mean, median, and sample size of the distribution, respectively. The gender of six subjects (4 psychology students and 2 economics students) could not be determined from their first names nor from their written answers in Hebrew, a language in which certain verb conjugations indicate the author's gender. Thus, $\mathrm{n}=204$. 


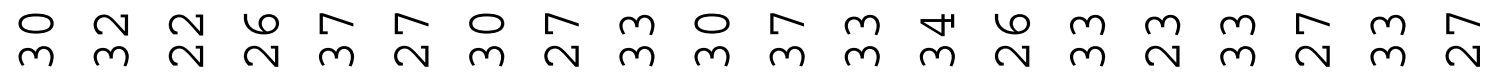

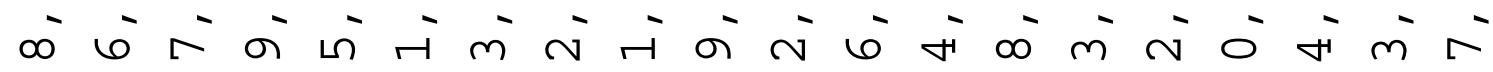

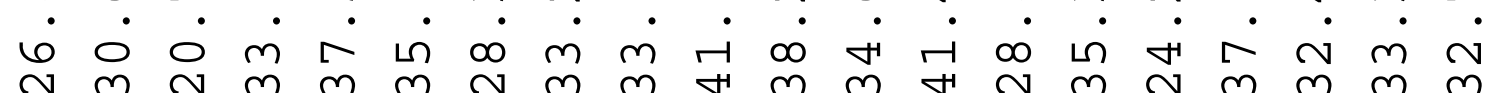

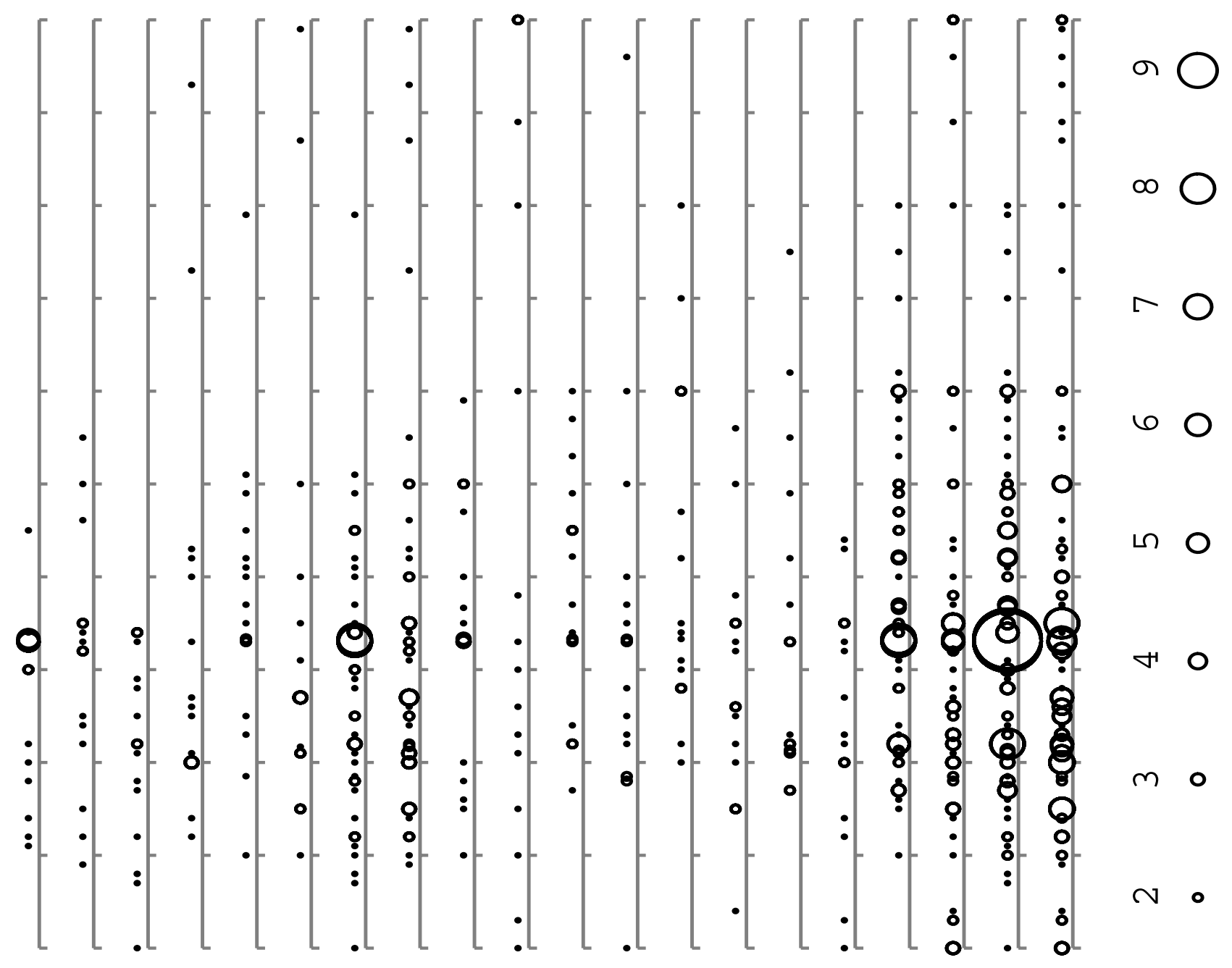

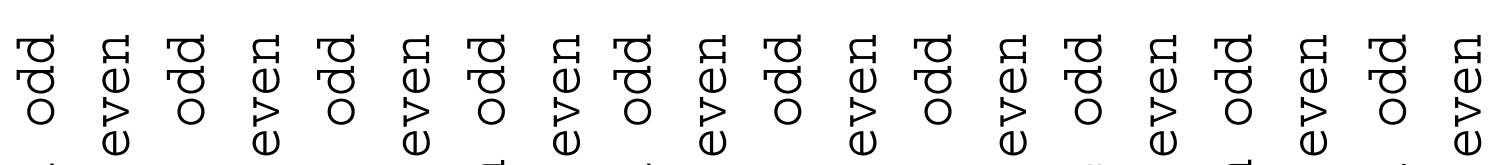

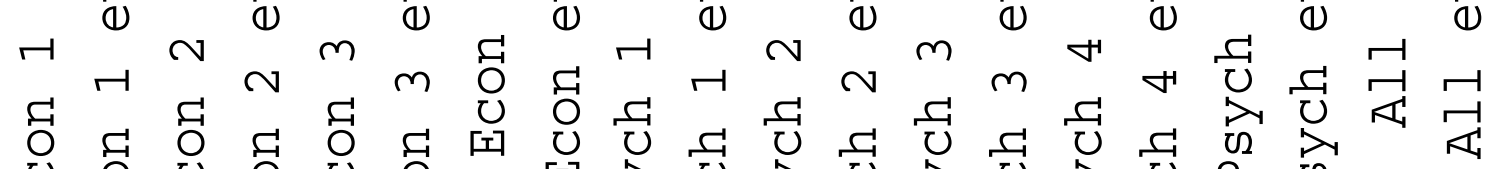

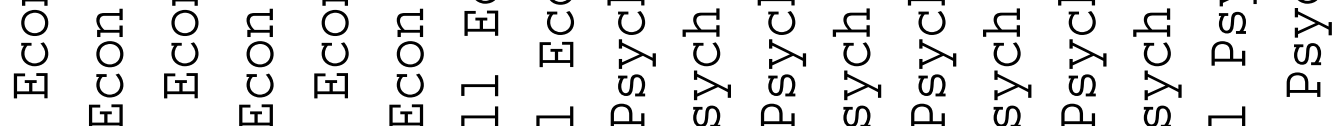

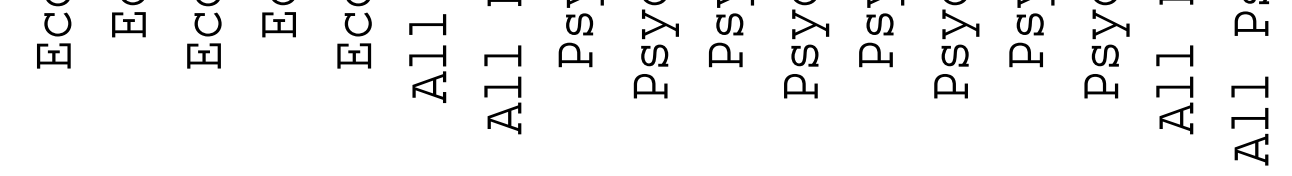




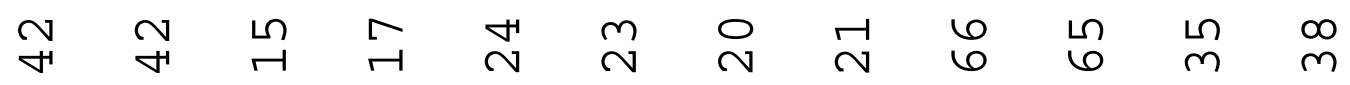

यो

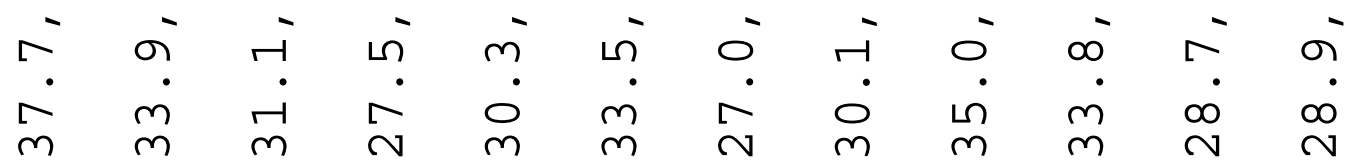
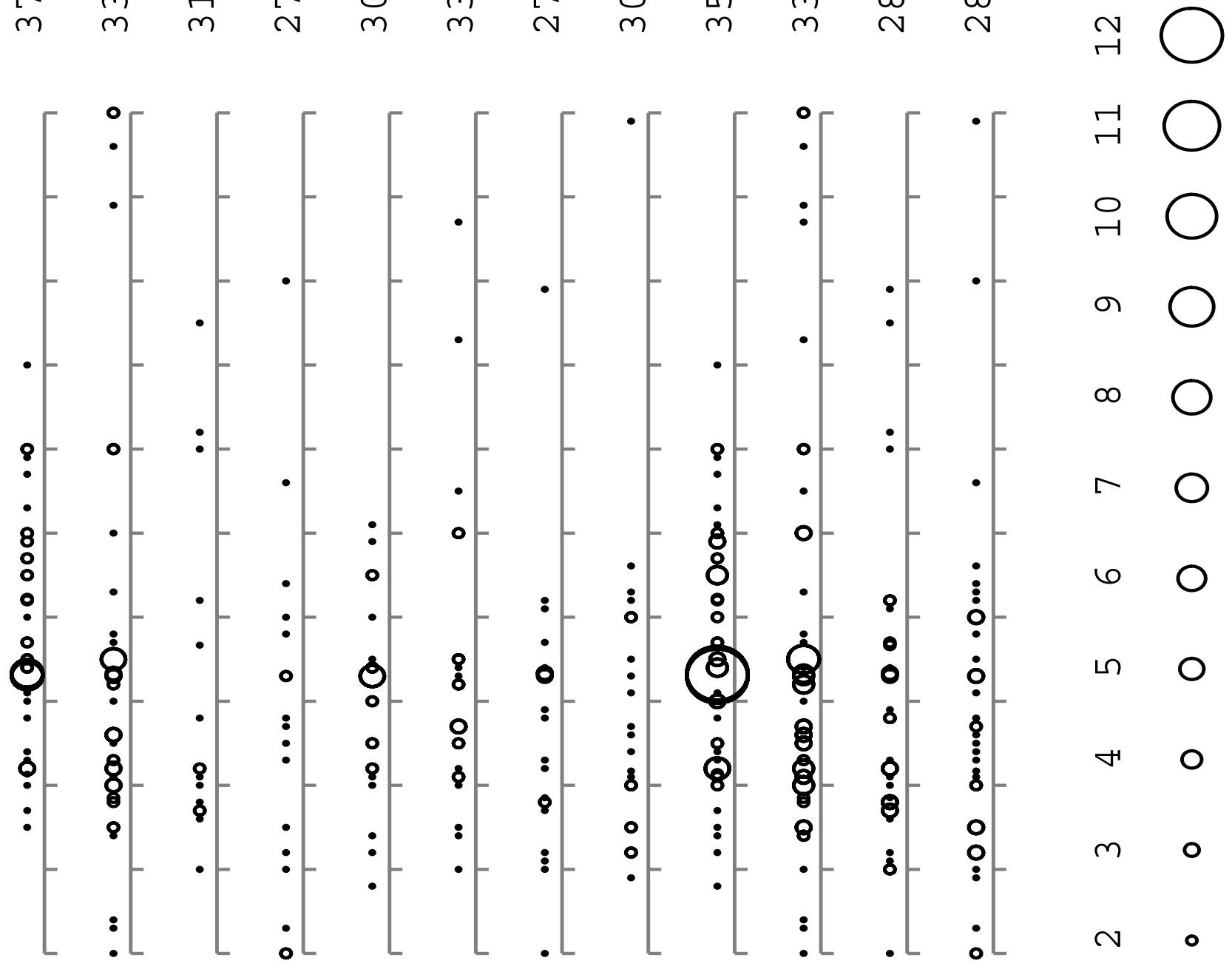

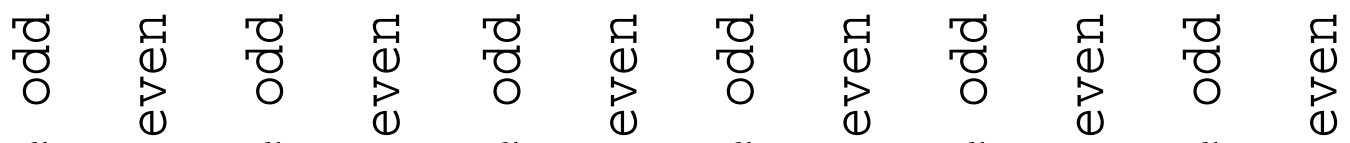

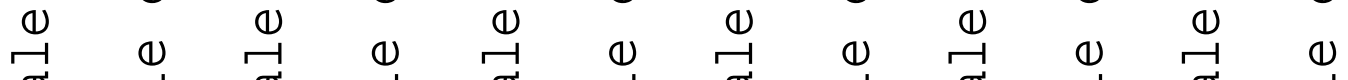

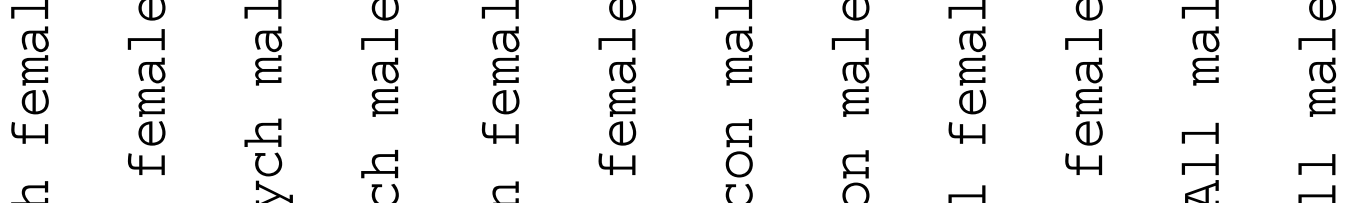

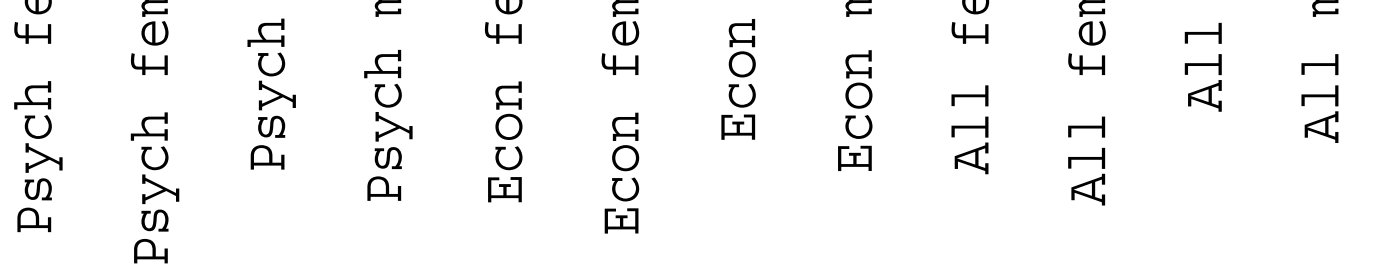

